\title{
Baseline glucose homeostasis predicts the new onset of diabetes during statin therapy: A retrospective study in real life
}

\author{
Maria Chantal Ponziani, ${ }^{1}$ Ioannis Karamouzis, ${ }^{1}$ Chiara Mele, ${ }^{1,2}$ Luisa Chasseur, ${ }^{1}$ \\ Marco Zavattaro, ${ }^{1}$ Marina Caputo, ${ }^{1}$ Maria Teresa Samà, ${ }^{1}$ Arianna Busti, ${ }^{1}$ \\ Loredana Pagano, ${ }^{1}$ Luigi Castello, ${ }^{1}$ Paolo Marzullo, ${ }^{1,2}$ Gianluca Aimaretti, ${ }^{1}$ Flavia Prodam ${ }^{3}$ \\ ${ }^{1}$ Department of Translational Medicine, University of Piemonte Orientale, Novara, Italy; ${ }^{2}$ Division of General Medicine, \\ Istituto Auxologico Italiano, Ospedale S. Giuseppe, Piancavallo (VB), Italy; ${ }^{3}$ Department of Health Sciences, University \\ of Piemonte Orientale, Novara, Italy
}

\begin{abstract}
OBJECTIVE. We evaluated the risk of altered glucose levels and new-onset diabetes (NOD) associated with statins according to glucose levels at baseline in a population treated for dyslipidemia on primary prevention for $>5$ years. DESIGN. The retrospective study included 308 subjects (265 on statins and 43 controls on diet) with a follow-up of 5-15 years. The cohort was classified according to glucose tolerance at both baseline and follow-up. RESULTS. The cumulative incidence of NOD was $13.6 \%(9.3 \%$ in controls and $13.5 \%$ in treated patients). NOD was diagnosed after $3.4 \pm 1.8$ years. In the group with normal glucose levels at baseline, a family history of diabetes (OR: $3.4,95 \%$ CI $1.3-8.9)$, BMI $>30 \mathrm{~kg} / \mathrm{m}^{2}(\mathrm{OR}: \mathbf{8 . 5}, 95 \%$ CI 2.0 35.8), treatment with thiazide (OR: 21.9, 95\% CI 1.2-384.2) and no alcohol consumption (OR: $0.3,95 \%$ CI 0.1-0.8) reduced the risk of developing altered glucose levels or NOD. No effects of statins were seen. In the group with altered glucose levels at baseline, hypertension (OR: 5.0, 95\% CI 1.0-25.3) and hypertriglyceridemia (OR: 3.5, 95\% CI 1.0-11.8) increased the risk of remaining with altered glucose levels or developing NOD. Treatment with statins (OR: 7.5, 95\% CI 1.5-37.4), in particular atorvastatin, was associated with an increased risk. In the whole population, statin therapy (OR: 4.0, 95\% CI 1.1-14.1, $p<0.020$ ), and in particular simvastatin and atorvastatin, was associated with increased risk of altered glucose levels or NOD. Patients who developed or maintained altered glucose levels or NOD had a poor metabolic phenotype at baseline. CONCLUSIONS. Statins were associated with an increased risk of NOD or altered glucose levels, mainly in subjects with altered glucose levels before the beginning of therapy. Poor metabolic phenotype and unhealthy behaviors or family history of diabetes contributed to that risk.
\end{abstract}

Key words: Altered glucose levels, Dyslipidemia, New-onset diabetes, Statin 


\section{INTRODUCTION}

Due to the high morbidity and mortality related to cardiovascular $(\mathrm{CV})$ diseases, prevention is a priority. In Europe, around $50 \%$ of deaths are caused by or are related to these pathologies (mainly coronary disease, responsible for $20 \%$ of deaths, followed by stroke). ${ }^{1}$

Statins represent one of the most important breakthroughs in the treatment of patients with high CV risk, as documented by many studies on both primary and secondary prevention. ${ }^{2,3}$ However, an association has been identified between statin therapy and new onset of type 2 diabetes mellitus (NOD),${ }^{4-8}$ which is a major CV risk factor. ${ }^{9}$

In February 2012, the US Food Drug Administration (FDA) issued a warning related to statin therapy and an increased risk of NOD. ${ }^{10}$ Nevertheless, it is useful to remember that most of the evidence has emerged from post-hoc analyses of studies not specifically designed to investigate NOD.

The aim of the present study was to evaluate the long-term effect of statin therapy on glucose metabolism in a heterogeneous group of dyslipidemic primary prevention patients referred to a tertiary center. The primary objective was the evaluation of NOD in patients treated with statin therapy for at least 5 years. The secondary objective was the detection of alterations in markers of prediabetes during statin treatment on the basis of anthropometric and biochemical parameters, concomitant treatment, family history, unhealthy behaviors and risk factors as described in the Treating to New Target (TNT), Incremental Decrease in End Points Through Aggressive Lipid Lowering Trial (IDEAL) and the Stroke Prevention by Aggressive Reduction in Cholesterol Levels (SPARCL) studies. ${ }^{7,11-14}$

\section{SUBJECTS AND METHODOLOGY}

We performed a retrospective longitudinal study from 2000 to 2014 in patients referred to the Lipidology outpatient clinic of the "Ospedale Maggiore della Carità", Novara, Italy. Study quality was assessed using the STROBE checklist. ${ }^{15}$ Patients were selected based on the following criteria: males and females aged 18-90 years, naïve to statin use before the baseline sample followed by continuous statin (cases) or diet therapy (controls) for at least 5 years. We selected patients on primary prevention; those with a known diagnosis of type 2 diabetes and/or cardiovascular diseases different from hypertension, dyslipidemia secondary to kidney failure or cystic fibrosis, family history of type 1 diabetes or active neoplasia were excluded. Patients with impaired fasting glucose or impaired glucose tolerance at baseline were accepted. Changes of statin dosage or molecule were allowed and patients were scheduled as treated with the last dosage or molecule at the end of the study. To be included in the study, patients and controls had be checked and scheduled at baseline and at the last visit for family history (type 2 diabetes and dyslipidemia), lifestyle habits (smoke and alcohol consumption), other diseases or treatments. They also had to have evaluations of the following clinical and biochemical parameters: weight, height, waist circumference, systolic blood pressure (SBP), diastolic blood pressure (DBP), fasting glucose, $\mathrm{HbA}_{1 \mathrm{c}}$, total cholesterol (T-c), High Density Lipoprotein-cholesterol (HDL-c), Low Density Lipoprotein-cholesterol (LDL-c), triglycerides (TG), serum creatinine, aspartate aminotransferase (AST) and alanine aminotransferase levels (ALT).

The initial cohort was composed of 1,879 subjects, of whom 1,571 were excluded because they did not fulfill the inclusion criteria. A total of 308 subjects were included in the study. The cohort was classified according to glucose tolerance at both baseline and follow-up. They were firstly divided into 2 groups, i.e. subjects with normal (A) and altered glucose levels (B). The subjects were further divided into patients who maintained (AA) or patients whose levels returned to normal (BA), patients who developed (AB) or who maintained altered glucose levels (BB) and patients who developed NOD (AC, BC).

Height was measured by the Harpenden stadiometer to the nearest $\mathrm{mm}$ and weight by using an electronic scale, both taken in triplicate. BMI was calculated as body weight divided by squared height $\left(\mathrm{kg} / \mathrm{m}^{2}\right)$. SBP and DBP were measured using a mercury free sphygmomanometer (UM-102A, A\&D Medical, Japan) with an appropriate cuff size after participants had been seated quietly for at least 15 min with their right arm supported at the level of the heart and feet flat on the floor, prior to other physical evaluations. 
NOD was diagnosed according to the American Diabetes Association (ADA) criteria for fasting plasma glucose $(\geq 126 \mathrm{mg} / \mathrm{dl}, 7.0 \mathrm{mmol} / \mathrm{l})$, post-glucose challenge ( 2 -h plasma glucose $\geq 200 \mathrm{mg} / \mathrm{dl}, 11.1 \mathrm{mmol} / \mathrm{l}$ ) during an oral glucose tolerance test (OGTT) or $\mathrm{HbA}_{\mathrm{lc}}$ levels $\geq 6.5 \%$.

Altered glucose levels were used for individuals with impaired fasting glucose (IFG; fasting plasma glucose $100 \mathrm{mg} / \mathrm{dL}$ or $5.6 \mathrm{mmol} / \mathrm{L}$ to $125 \mathrm{mg} / \mathrm{dL}, 6.9$ $\mathrm{mmol} / \mathrm{l}$ ) and/or impaired glucose tolerance (IGT; 2-h PG in the $75 \mathrm{~g}$ OGTT $140 \mathrm{mg} / \mathrm{dl} / 7.8 \mathrm{mmol} / \mathrm{l}$ to 199 $\mathrm{mg} / \mathrm{dl} / 11.0 \mathrm{mmol} / \mathrm{l}$ ) according to the ADA criteria. ${ }^{16}$ LDL-c was determined either by a laboratory test or with the Friedewald formula; non-HDL-c, LDL- to HDL-c ratio and T-c to HDL-c ratio were also calculated. Prediction risk factors for NOD were evaluated according to the TNT, SPARCL and IDEAL studies $^{7,11-14}$ as fasting glucose $>100 \mathrm{mg} / \mathrm{dl}(5.6 \mathrm{mmol} / \mathrm{l})$, blood pressure levels $>140 / 90 \mathrm{mmHg}$ or treatments for hypertension, BMI $>30 \mathrm{~kg} / \mathrm{m}^{2}$ and TG $>150 \mathrm{mg} / \mathrm{dl}$.

Biochemical analyses were performed using standardized methods in the Hospital's Laboratory. Plasma glucose levels (mg/dl; $1 \mathrm{mg} / \mathrm{dl}: 0.05551 \mathrm{mmol} / \mathrm{l})$ were measured by the gluco-oxidase colorimetric method (GLUCOFIX, by Menarini Diagnostici, Florence, Italy). $\mathrm{HbA}_{1 \mathrm{c}}$ levels were measured by high-performance liquid chromatography (HPLC) using a Variant machine (Biorad, Hercules, CA); intra- and inter-assay coefficients of variation are respectively lower than 0.6 and $1.6 \%$. Linearity is excellent from $3.2 \%$ (11 $\mathrm{mmol} / \mathrm{mol})$ to $18.3 \%$ (177 mmol $/ \mathrm{mol})$. Serum creatinine levels were assessed using the enzymatic method of creatinine deamidase/GLDH (Adivia Chemistry Bayer). Plasma T-c (mg/dl; $1 \mathrm{mg} / \mathrm{dl}: 0.0259 \mathrm{mmol} / \mathrm{l})$ concentration was measured by esterase and oxidase conversion (Advia 1650, Bayer Diagnostics, Newbury, UK); coefficient of variation $1.9 \%$. Plasma TG (mg/ $\mathrm{dl} ; 1 \mathrm{mg} / \mathrm{dl}: 0.0113 \mathrm{mmol} / \mathrm{l})$ and HDL-c $(\mathrm{mg} / \mathrm{dl} ; 1 \mathrm{mg} /$ dl: $0.0259 \mathrm{mmol} / \mathrm{l})$ concentrations were measured by enzymatic determination (Advia 1650, Bayer Diagnostics, Newbury, UK); coefficient of variation 1.7\%. AST and ALT levels were measured by enzymatic methods (Roche Diagnostics, Mannheim, Germany).

The study was conducted in accordance with the declaration of Helsinki. It was approved by the Local Inter-Hospital Ethic Committee (Maggiore Hospital
Ethical Committee) and written informed consent was obtained from all subjects.

\section{Statistical analysis}

Results are expressed as mean and standard deviation $(\mathrm{SD})$ or $95 \%$ confidence interval $(95 \% \mathrm{CI})$. Distributions of continuous variables were examined for skewness and were logarithmically transformed as appropriate. Analysis of variance was used to determine differences between groups. Logistic regression analysis was used to determine the association of altered glucose levels/NOD with the odds ratio (OR, 95\% CI) of the following risk factors: diet/ treatment with statin, alcohol, thiazide therapy and risk factors derived from TNT, IDEAL and SPRCL studies (model 1). Model 2 also included the family history of type 2 diabetes or dyslipidemia. All the models were corrected for age, sex, PUFA-n3 or treatment with ezetimibe, smoking habits and years of follow-up. Statins were also classified according to molecules (fluvastatin + pravastatin; simvastatin, atorvastatin, rosuvastatin). Logistic regression analysis was performed in the whole population or in the two subgroups (controls on diet/patients on statins) to refine the risk. Diet/statin therapy was evaluated in both main effect and custom models (interaction of all fixed factors and covariates).

Cox regression models were fitted to the time of observation to the outcome of NOD. The ascertainment of the year of diagnosis of NOD was derived from the files of all patients who had obtained an exemption from payment for drugs, syringes and glucose monitoring strips because of a diagnosis of diabetes mellitus. Cox regression models were not performed for the outcome NOD + altered glucose levels because the year of diagnosis of altered glucose levels was uncertain.

Statistical significance was defined as $\mathrm{p}<0.05$ (2-sided models). The statistical analysis was performed with SPSS for Windows version 17.0 (SPSS Inc., Chicago, IL, USA).

\section{RESULTS}

The first dataset included 1,879 subjects of whom 1,571 patients were excluded because they did not satisfy the inclusion criteria: 1,206 subjects for a 
follow-up $<5$ years, 26 for incomplete clinical or biochemical data, 20 for statin withdrawal before 5 years and 319 for the presence of type 2 diabetes at baseline. The final dataset of 308 subjects ( 130 males, 178 females, age: $53.9 \pm 12.6$ years), with 265 patients on statin therapy and 43 on diet (controls), included 216 patients in group A (normal glucose levels) and 92 of group B (altered glucose levels). Moreover, 123 patients had a family history of type 2 diabetes and 164 of dyslipidemia.

With respect to therapy, 65 patients had been treated with atorvastatin, 85 with simvastatin, 62 with rosuvastatin, 37 with pravastatin and 16 with fluvastatin, respectively. Additionally, 16 patients had been further treated with ezetimibe, 25 patients and 6 controls with PUFA-n3, 9 patients had been taking thiazide diuretics and 2 patients beta-blockers for hypertension. No patients had been on chronic corticosteroid treatments.

\section{Clinical and metabolic characteristics of patients with normal and altered glucose levels at baseline}

Age, weight, BMI, waist circumference, SBP, DBP, fasting glucose, $\mathrm{HbA}_{1 \mathrm{c}}$ and AST levels were higher $(p<0.020)$, while T-c, LDL-c, HDL-c and non-HDL-c $(p<0.030)$ were lower in group B than A, respectively, in the cohort as a whole or divided according to cases and controls (Table 1).

Altered glucose levels at baseline were associated with family history of type 2 diabetes (OR: $2.81,95 \%$ CI 1.58-4.98, $\mathrm{p}<0.001)$ and dyslipidemia (OR: 0.3, $95 \%$ CI $0.168-0.536 ; p<0.001)$. No associations with smoking or alcohol consumption were noted.

\section{Clinical and metabolic characteristics of patients with normal and altered glucose levels at follow-up}

At the last follow-up visit, those in group B had higher body weight, BMI, waist circumference, glucose, $\mathrm{HbA}_{1 \mathrm{c}}$, blood pressure, TG, ALT, while they had lower T-c, LDL-c, HDL-c, and T-c to HDL-c ratio levels than those in group A (Table 2).

By considering subjects with normal glucose levels at follow-up (AA and BA), those treated with statins had higher BMI $\left(24.6 \pm 3.7\right.$ vs $23.4 \pm 5.0 \mathrm{Kg} / \mathrm{m}^{2}$, $\mathrm{p}=0.050)$ but lower T-c $(199.6 \pm 43.1 \mathrm{vs} 227.3 \pm 48.1 \mathrm{mg} /$
Table 1. Clinical and metabolic characteristics of patients with normal and altered glucose levels at baseline

\begin{tabular}{|c|c|c|c|}
\hline Variable & Group A & Group B & p \\
\hline Subjects $(\mathrm{M} / \mathrm{F})$ & $216(88 / 128)$ & $92(42 / 50)$ & 0.760 \\
\hline Age (yrs) & $54.0 \pm 12.6$ & $57.2 \pm 11.1$ & 0.004 \\
\hline Weight (Kg) & $67.7 \pm 12.2$ & $75.2 \pm 17.0$ & 0.0001 \\
\hline BMI (Kg/m2) & $24.6 \pm 3.5$ & $27.6 \pm 6.2$ & 0.0001 \\
\hline $\mathrm{WC}(\mathrm{cm})$ & $83.4 \pm 12.1$ & $97.1 \pm 12.1$ & 0.0001 \\
\hline SBP (mmHg) & $128.1 \pm 16.3$ & $134.8 \pm 16.8$ & 0.0001 \\
\hline DBP (mmHg) & $78.6 \pm 8.3$ & $80.8 \pm 7.8$ & 0.016 \\
\hline FPG (mg/dl) & $87.1 \pm 8.0$ & $111.0 \pm 8.6$ & 0.0001 \\
\hline $\mathrm{HbA}_{1} \mathrm{c}(\%)$ & $5.5 \pm 0.3$ & $6.0 \pm 0.5$ & 0.0001 \\
\hline $\mathrm{T}-\mathrm{c}(\mathrm{mg} / \mathrm{dl})$ & $273.9 \pm 55.8$ & $255.8 \pm 53.3$ & 0.006 \\
\hline HDL-c (mg/dl) & $59.8 \pm 17.2$ & $54.7 \pm 17.9$ & 0.013 \\
\hline LDL-c (mg/dl) & $183.3 \pm 55.1$ & $167.7 \pm 53.1$ & 0.014 \\
\hline Non HDL-c (mg/dl) & $215.2 \pm 54.1$ & $200.6 \pm 58.4$ & 0.023 \\
\hline LDL-c/HDL-c & $3.23 \pm 1.16$ & $3.23 \pm 1.46$ & 0.654 \\
\hline T-c/HDL-c & $4.87 \pm 1.41$ & $4.99 \pm 1.96$ & 0.792 \\
\hline TG (mg/dl) & $165.1 \pm 138.8$ & $176.3 \pm 105.5$ & 0.258 \\
\hline Creatinine $(\mathrm{mg} / \mathrm{dl})$ & $1.0 \pm 0.2$ & $1.0 \pm 0.2$ & 0.243 \\
\hline eGFR (ml/min) & $75.4 \pm 15.9$ & $70.0 \pm 14.4$ & 0.520 \\
\hline $\mathrm{AST}(\mathrm{U} / \mathrm{L})$ & $23.1 \pm 8.2$ & $24.0 \pm 6.3$ & 0.191 \\
\hline ALT (U/L) & $24.3 \pm 12.5$ & $28.5 \pm 10.8$ & 0.002 \\
\hline
\end{tabular}

ALT: alanine aminotransferase; AST: aspartate aminotransferase; BMI: Body Mass Index; DBP: Diastolic Blood Pressure; eGFR: estimated Glomerular Filtration Rate; FPG: Fasting Plasma Glucose; HbA1c: Haemoglobin A1c; HDL-c: HDL cholesterol; SBP: Systolic Blood Pressure; T-c: total cholesterol, Group A: patients with normal glucose levels; TG: triglycerides. Group B: patients with altered glucose levels. Data are expressed as mean \pm SD.

$\mathrm{dl}, \mathrm{p}<0.001)$, LDL-c $(114.1 \pm 41.3$ vs $139.0 \pm 38.4 \mathrm{mg} /$ $\mathrm{dl} \mathrm{p}<0.001)$, non-HDL-c (129.1 \pm 55.6 vs $164.2 \pm 44.2$ $\mathrm{mg} / \mathrm{dl}, \mathrm{p}<0.001)$, LDL-c to HDL-c ratio $(2.0 \pm 1.1 \mathrm{vs}$ $2.4 \pm 1.2, \mathrm{p}<0.048), \mathrm{T}-\mathrm{c}$ to HDL-c ratio $(1.9 \pm 0.2 \mathrm{vs}$ $4.0 \pm 1.5 ; \mathrm{p}<0.047$ ) than controls.

By considering subjects with altered glucose levels at follow-up (AB, AC, BB and $\mathrm{BC})$, those treated with statins had lower T-c $(190.9 \pm 35.5$ vs $211.8 \pm 38.4 \mathrm{mg} /$ $\mathrm{dl}, \mathrm{p}<0.020)$, LDL-c $(108.1 \pm 32.1 \mathrm{vs} 128.4 \pm 39.0 \mathrm{mg} /$ $\mathrm{dl} \mathrm{p}<0.022)$, non-HDL-c (133.7 \pm 37.0 vs $161.4 \pm 35.8$ $\mathrm{mg} / \mathrm{dl}, \mathrm{p}<0.004)$, LDL-c to HDL-c ratio $(2.0 \pm 0.7$ vs $2.6 \pm 0.8, \mathrm{p}<0.006), \mathrm{T}-\mathrm{c}$ to HDL-c ratio $(1.9 \pm 0.2$ vs $3.8 \pm 1.3 ; \mathrm{p}<0.004)$ and AST levels $(22.6 \pm 8.3$ vs $25.9 \pm 7.0 \mathrm{U} / \mathrm{L}, \mathrm{p}<0.009)$ than controls. 
Table 2. Clinical and metabolic characteristics of patients with normal (Group A) and altered glucose levels (Group B) at the follow-up

\begin{tabular}{|c|c|c|c|}
\hline Variable & Group A & Group B & $\mathbf{p}$ \\
\hline Subjects $(\mathrm{M} / \mathrm{F})$ & $187(71 / 116)$ & $121(59 / 62)$ & \\
\hline Weight (Kg) & $67.3 \pm 13.7$ & $74.8 \pm 14.7$ & $<00001$ \\
\hline BMI (Kg/m2) & $24.4 \pm 3.9$ & $27.6 \pm 4.8$ & $<0.001$ \\
\hline $\mathrm{WC}(\mathrm{cm})$ & $90.7 \pm 13.5$ & $100.3 \pm 11.3$ & $<0.001$ \\
\hline SBP (mmHg) & $124.2 \pm 18.4$ & $133.3 \pm 16.2$ & $<0.001$ \\
\hline DBP (mmHg) & $78.0 \pm 7.2$ & $80.1 \pm 8.2$ & 0.010 \\
\hline FPG (mg/dl) & $89.4 \pm 7.7$ & $116.6 \pm 15.5$ & $<0.001$ \\
\hline HbA1c (\%) & $5.5 \pm 0.2$ & & $<0.001$ \\
\hline T-c (mg/dl) & $204.0 \pm 45.0$ & $193.5 \pm 36.4$ & 0.010 \\
\hline HDL-c (mg/dl) & $62.3 \pm 21.0$ & $54.2 \pm 14.5$ & $<0.001$ \\
\hline LDL-c (mg/dl) & $118.1 \pm 41.8$ & $110.7 \pm 33.6$ & 0.040 \\
\hline Non HDL-c (mg/dl) & $134.4 \pm 55.4$ & $137.1 \pm 37.8$ & 0.366 \\
\hline LDL-c/HDL-c & $2.1 \pm 1.1$ & $2.1 \pm 0.7$ & 0.051 \\
\hline T-c/HDL-c & $3.5 \pm 1.3$ & $3.7 \pm 0.9$ & 0.004 \\
\hline TG (mg/dl) & $129.1 \pm 87.7$ & $147.7 \pm 67.3$ & 0.001 \\
\hline Creatinine (mg/dl) & $0.8 \pm 0.2$ & $0.8 \pm 0.1$ & 0.351 \\
\hline eGFR (ml/min) & $86.9 \pm 16.8$ & $84.9 \pm 17.5$ & 0.141 \\
\hline $\operatorname{AST}(\mathrm{U} / \mathrm{L})$ & $21.9 \pm 6.8$ & $23.1 \pm 8.2$ & 0.163 \\
\hline $\operatorname{ALT}(\mathrm{U} / \mathrm{L})$ & $22.6 \pm 11.2$ & $31.2 \pm 18.2$ & 0.003 \\
\hline
\end{tabular}

ALT: alanine aminotransferase; AST: aspartate aminotransferase; BMI: Body Mass Index; DBP: Diastolic Blood Pressure; eGFR: estimated Glomerular Filtration Rate; FPG: Fasting Plasma Glucose; HbA1c: Haemoglobin A1c; HDL-c: HDL cholesterol; SBP: Systolic Blood Pressure; T-c: total cholesterol, Group A: patients with normal glucose levels; TG: triglycerides. Group B: patients with altered glucose levels. Data are expressed as mean \pm SD.

\section{Baseline clinical and metabolic characteristics of patients according to glucose levels at follow-up}

The median time of observation was $6.0 \pm 1.6$ years (5-15 years). In group A, 169 patients (AA: 146 on therapy, 23 controls) maintained normal glucose levels, 42 (AB: 38 on therapy, 4 controls) developed altered glucose levels and 5 (AC: 1 on therapy, 4 controls) had NOD. Conversely, in group B, 18 patients (BA: 13 on therapy, 5 controls) returned to normal glucose levels, 37 (BB: 30 on therapy, 7 controls) maintained altered glucose levels and 37 (BC: 36 on therapy, 1 control) developed NOD. The cumulative incidence of NOD during follow-up was $13.6 \%$ (11.6\% in controls and $13.9 \%$ in treated patients). NOD was diagnosed after a median time of $3.4 \pm 1.8$ years after the first visit.

All the AA subjects presented lower BMI (24.1 \pm 3.3 vs $26.1 \pm 3.4 \mathrm{Kg} / \mathrm{m}^{2} ; \mathrm{p}<0.001$ ), waist circumference $(81.2 \pm 10.7$ vs $97.8 \pm 9.0 \mathrm{~cm} ; \mathrm{p}<0.001), \operatorname{SBP}(126.5 \pm 16.8$ vs $134.4 \pm 13.3 \mathrm{mmHg}$; $<0.001)$, DBP $(78.0 \pm 8.1$ vs $80.9 \pm 8.6 \mathrm{mmHg} ; \mathrm{p}<0.020)$, glucose $(86.1 \pm 7.9$ vs $91.1 \pm 6.8 \mathrm{mg} / \mathrm{dl} ; \mathrm{p}<0.001)$, while they had higher HDL-c levels (61.1 \pm 17.5 vs $55.9 \pm 15.7 \mathrm{mg} / \mathrm{dl} \mathrm{p}<0.038)$ than in group AB. AA subjects also had lower BMI $\left(24.1 \pm 3.3\right.$ vs $\left.28.4 \pm 3.5 \mathrm{Kg} / \mathrm{m}^{2} ; \mathrm{p}<0.004\right)$ and higher T-c $(274.8 \pm 54.7$ vs $242.2 \pm 102.1 \mathrm{mg} / \mathrm{dl} ; \mathrm{p}<0.041)$ and HDL-c levels $(61.1 \pm 17.5$ vs $47.0 \pm 12.3 \mathrm{mg} / \mathrm{dl}$, $\mathrm{p}<0.038$ ) than AC subjects at baseline. Furthermore, the AA group as a whole and as a treatment group presented a lower prevalence of obesity $(p<0.003)$, thiazide diuretics intake $(\mathrm{p}<0.033)$ and family history of type 2 diabetes $(\mathrm{p}<0.021)$ and a higher prevalence of family history of dyslipidemia $(\mathrm{p}<0.014)$ than $\mathrm{AB}$ plus AC subjects.

The BB group had lower BMI ( $26.3 \pm 4.8$ vs $28.5 \pm 4.0$ $\left.\mathrm{Kg} / \mathrm{m}^{2} ; \mathrm{p}<0.004\right)$, waist circumference $(91.3 \pm 11.7 \mathrm{vs}$ $103.8 \pm 5.4 \mathrm{~cm} ; \mathrm{p}<0.006)$, glucose levels $(109.7 \pm 6.7$ vs $115.5 \pm 9.1 \mathrm{mg} / \mathrm{dl} ; \mathrm{p}<0.001), \mathrm{HbA}_{1 \mathrm{c}}(5.8 \pm 0.3$ vs $6.2 \pm 0.4 \%$; $<0.001)$, LDL-c to HDL-c ratio $(3.0 \pm 1.0$ vs $3.7 \pm 1.8 ; \mathrm{p}<0.020)$, T-c to HDL-c ratio $(4.6 \pm 1.2 \mathrm{vs}$ $5.6 \pm 2.6 ; \mathrm{p}<0.009)$, and higher HDL-c $(57.1 \pm 19.5 \mathrm{vs}$ $48.2 \pm 12.5 \mathrm{mg} / \mathrm{dl} ; \mathrm{p}<0.004)$ than BC. The BB group had higher SBP $(135.3 \pm 18.0$ vs $125.5 \pm 12.4 \mathrm{mmHg}$; $\mathrm{p}<0.029)$, glucose $(109.7 \pm 6.7$ vs $106.1 \pm 4.5 \mathrm{mg} / \mathrm{dl}$; $\mathrm{p}<0.014)$, TG (177.6 \pm 98.6 vs $144.4 \pm 109.5 \mathrm{mg} / \mathrm{dl}$; $\mathrm{p}<0.040), \operatorname{AST}(24.9 \pm 6.6$ vs $20.4 \pm 5.7$ IU/L; $<<0.010)$ and ALT levels ( $28.8 \pm 9.2$ vs $20.9 \pm 9.1 \mathrm{IU} / \mathrm{L} ; \mathrm{p}<0.001)$ than BA at baseline.

In addition, the $\mathrm{AB}$ group had lower weight $(p<0.020)$, BMI $(p<0.001)$, SBP $(p<0.002)$, glucose $(\mathrm{p}<0.0001), \mathrm{HbA}_{1 \mathrm{c}}(\mathrm{p}<0.018)$, ALT $(25.8 \pm 11.8 \mathrm{vs}$ $32.7 \pm 10.9 \mathrm{UI} / \mathrm{L} \mathrm{p}<0.001)$, and higher T-c $(274.5 \pm 53.5$ vs $258.5 \pm 50.9 \mathrm{mg} / \mathrm{dl} \mathrm{p}<0.041)$ and HDL-c levels $(\mathrm{p}<0.011)$ than $\mathrm{BC}$.

\section{Risk factors associated with the development of altered glucose levels}

\section{Risk factors associated with altered glucose levels and NOD}

By evaluating the whole population, family history of type 2 diabetes (OR: 3.1, 95\% CI 1.3-7.2, $\mathrm{p}<0.006$ ), 
BMI $>30 \mathrm{~kg} / \mathrm{m}^{2}$ (OR: 5.2, 95\% CI 1.5-17.8, $\left.<<0.006\right)$, glucose levels $>100 \mathrm{mg} / \mathrm{dl}$ (OR: 22.6, 95\% CI 8.559.6, $\mathrm{p}<0.006$ ), treatment with statins (OR: 4.0, 95\% CI 1.1-14.1, $\mathrm{p}<0.029)$ increased, whereas no alcohol consumption (OR: $0.4,95 \%$ CI 0.2-0.9, $\mathrm{p}<0.025$ ) decreased, the risk of maintaining/developing altered glucose levels or developing NOD. Thiazide intake was marginally significant (OR: $14.1,95 \%$ CI 0.9 $210.4, \mathrm{p}=0.052)$. The intake of statins (OR: $4.0,95 \%$ CI 1.1-14.1, $\mathrm{p}<0.029)$, and in particular simvastatin and atorvastatin, was associated with increased risk in the full custom models (Table 3). By using the number of TNT factors the presence of increasing TNT risk factors increased the risk $(\mathrm{p}<0.0001)$.

In group A, a family history of type 2 diabetes (OR: $3.4,95 \%$ CI $1.3-8.9, \mathrm{p}<0.010$ ), BMI $>30 \mathrm{~kg} / \mathrm{m}^{2}$ (OR: $8.5,95 \%$ CI $2.0-35.8, \mathrm{p}<0.003$ ), thiazide therapy (OR: $21.9,95 \%$ CI 1.2-384.2, $\mathrm{p}<0.034$ ) increased, whereas no alcohol consumption (OR: $0.3,95 \% \mathrm{CI}$ $0.1-0.8, \mathrm{p}<0.010)$ reduced, the risk of developing altered glucose levels or NOD. No effects of statins (OR: 1.1, 95\% CI 0.4-3.4, p=0.753) were seen in any of the models. In group B, hypertension (OR: 5.0, $95 \%$ CI 1.0-25.3, $\mathrm{p}<0.049$ ) and hypertriglyceridemia (OR: 3.5, 95\% CI 1.0-11.8, $\mathrm{p}<0.040$ ) increased the risk of maintaining altered glucose levels or developing NOD. Treatment with statins (OR: 7.5, 95\% CI $1.5-37.4, \mathrm{p}<0.012$ ), and in particular atorvastatin, was associated with the increased risk in the full custom models (Table 3).

\section{Risk factors associated with NOD}

The analysis was performed in group B due to the relatively few cases of NOD in group A by the end of follow-up ( 4 controls and 1 treated patient).

In group B, having a BMI $>30 \mathrm{Kg} / \mathrm{m}^{2}$ (HR: 2.7 , 95\% CI 1.2-6.0, $\mathrm{p}<0.009$ ) and hypertension (HR: 2.5 , $95 \%$ CI 1.1-5.3, $\mathrm{p}<0.021)$ increased the risk of developing NOD. Statin therapy did not reach significance with respect to diet, possibly due to the sample size (37 events censored on statin and 1 event censored on diet therapy).

\section{DISCUSSION}

In our retrospective study on a cohort of dyslipidemic patients treated with statins or diet and with a follow-up longer than 5 years, those who developed or maintained altered glucose levels or NOD had a poor metabolic phenotype at baseline. Statin therapy, in particular atorvastatin, was associated with altered glucose levels or NOD in those who had altered fasting glucose at baseline, suggesting that this population should be carefully monitored.

The cumulative incidence of NOD was $13.6 \%$, $11.6 \%$ in controls and $13.9 \%$ in those treated with statins.

A meta-analysis of 13 randomized controlled trials with $>90,000$ participants found a $9 \%$ risk of incident NOD after 4 years of statin treatment, particularly in

Table 3. Risk to maintain altered glucose levels or to have new onset diabetes in logistic regression.

\begin{tabular}{|c|c|c|c|c|c|c|c|c|c|}
\hline & \multicolumn{3}{|c|}{ All subjects } & \multicolumn{3}{|c|}{ Group A } & \multicolumn{3}{|c|}{ Group B } \\
\hline & OR & CI95\% & $\mathbf{p}$ & OR & CI95\% & $\mathbf{p}$ & OR & CI95\% & $\mathbf{p}$ \\
\hline Diet & 1.000 & & & 1.000 & & & 1.000 & & \\
\hline Prava+Fluva & 2.045 & $0.417-10.023$ & 0.378 & 0.566 & $0.205-2.383$ & 0.698 & 1.750 & $0.385-7.951$ & 0.469 \\
\hline Simvastatin & 5.797 & $1.434-23.438$ & 0.010 & 0.898 & $0.318-2.534$ & 0.898 & 5.625 & $0.894-35.389$ & 0.067 \\
\hline Atorvastatin & 4.343 & $1.024-18.422$ & 0.042 & 0.975 & $0.314-3.027$ & 0.966 & 7.812 & $1.262-48.356$ & 0.023 \\
\hline Rosuvastatin & 3.851 & $0.807-18.365$ & 0.911 & 0.886 & $0.300-2.616$ & 0.827 & 1.875 & $0.396-10.463$ & 0.474 \\
\hline
\end{tabular}

CI: confidence interval; OR: odds ratio; Prava+Fluva: pravastatin+ fluvastatin; Group A: subjects (216) with normal glucose levels at baseline; Group B: subjects (92) with altered glucose levels at baseline. The models also included the following fixed factors and covariates: age, sex, BMI $>30 \mathrm{Kg} / \mathrm{m}^{2}$, hypertension, hypertriglyceridemia, thiazide, PUFA-n3 or ezetimibe assumption, alcohol consumption, smoking, years of follow-up for Group A and B, and also for glucose $>100 \mathrm{mg} / \mathrm{dl}$ for all subjects.

Table 3 represents OR only for statin assumption (independent variable). 
those who were older ${ }^{4}$ and on intensive-dose statin therapy. ${ }^{5}$ The higher incidence in our cohort could be explained by the longer follow-up (median: 6 years, range 5-15 years). Furthermore, because our patients were referred to a tertiary referral center for dyslipidemia, a selection bias due to a higher risk metabolic phenotype cannot be excluded. In addition, our patients were subjected to a careful staging of $\mathrm{CV}$ risk factors and an OGTT was also performed for any increase in fasting plasma glucose. Moreover, the incidence of NOD in patients treated with diet was higher than that reported in other studies in European countries. ${ }^{17,18}$ This difference could be due to difficulties in the ascertainment of the incidence of NOD in the general population and dyslipidemic patients could be a population at higher risk when diet adherence is not good, as shown in the "Primary prevention of cardiovascular disease with pravastatin in Japan" (MEGA) study. ${ }^{19}$

Cederberg et a $1^{18}$ published similar data based on the follow-up of the METabolic Syndrome In Men (METSIM) study conducted in men randomly selected from the Kuopio, Finland, population register. They observed an increased risk of NOD in those treated with statins, but also a worsening of hyperglycemia at oral glucose tolerance test (OGTT) that represented a progressive prediabetic state. We confirm this observation in a selected population of dyslipidemic patients of both sexes on primary prevention and with a longer follow-up. The most important finding of our study is that the glucose phenotype at baseline was crucial in predicting the risk of developing altered glucose levels with statins, whereas the risk was not present when fasting glucose levels were $<100 \mathrm{mg} / \mathrm{dl}(5.6$ $\mathrm{mmol} / \mathrm{l})$. A post hoc analysis of the patients without diabetes at baseline from both the TNT and IDEAL trials reported similar findings. ${ }^{20}$

Our analysis of anthropometric and metabolic parameters showed that patients who developed altered glucose levels or NOD had an insulin resistance phenotype at baseline. In particular, they had more central obesity and hypertension as well as lower HDL-c levels and maintained these characteristics over time. These findings suggest that statins could more rapidly worsen a metabolic phenotype already known to predict the risk of NOD. ${ }^{19,21,22}$ Because we also observed that a higher number of TNT risk factors increased the risk, clinicians should carefully monitor patients with this phenotype since a synergistic action of statins with other diabetes risk factors is likely.

A family history of type 2 diabetes is recognized as a risk factor for NOD development. It has been demonstrated that the risk is three times higher in people who have a relative affected by type 2 diabetes and 6 times higher in people who have both parents affected. ${ }^{23,24}$ In our series, a family history of type 2 diabetes should be another factor to consider in the global management of patients treated with statins.

Alcohol abuse has been identified as a possible risk factor for NOD since it results in an extreme intake of carbohydrates, obesity, increasing pancreatitis incidence and worsening of hepatic function together with an alteration of glucose metabolism. ${ }^{25}$ Interestingly, although we were unable to stratify daily alcohol intake due to the retrospective nature of the study, no alcohol consumption was protective. This factor should be considered in the follow-up of patients treated with statins. Studies with dose-response analyses are needed, especially since it was recently observed that a moderate reduction risk of NOD is present but confined to women with moderate levels of alcohol consumption. ${ }^{26}$

Moreover, we showed that statins, mainly atorvastatin, are linked to a higher risk of NOD or altered glucose levels in agreement with the majority of the literature. Pravastatin and pitavastatin even showed a protective effect on glucose alteration development. ${ }^{27-29}$ The reason why some, but not all, statins have detrimental effects on glucose metabolism remains unresolved. Beyond molecule-dependent mechanisms, other possible explanations include residual confounding factors, including a different lifestyle and an aggressive statin treatment.

We also reported a lower risk of having altered glucose levels at baseline, before any treatment with statins, in those with a family history of dyslipidemia. These results are in line with several observational studies that reported an inverse association between familial hypercholesterolemia and the risk of type 2 diabetes with a certain genotype-phenotype correlation. ${ }^{30}$ Moreover, the SAFEHEART cohort study showed that statins do not increase the risk of type 2 diabetes mellitus in patients with familial hyper- 
cholesterolemia. ${ }^{31}$ These data point to the intriguing hypothesis that LDL receptor (LDLR) mutations can improve the function of pancreatic $\beta$ cells. ${ }^{30}$

The current study has some limitations. First, due to its retrospective nature we could not control for adherence to treatment. Secondly, because the cases of altered glucose levels could not be ascertained in registries or with medical prescriptions, Cox regression models for this condition were not performed. Additionally, we studied only a few controls, but this is linked to the nature of a population followed in a tertiary referral center. Conversely, the study included a number of patients with a follow-up $>5$ years. Finally, many risk factors including family history of type 2 diabetes were considered.

In conclusion, this study confirmed that statins are associated with an increased risk of NOD or altered glucose levels, mainly in subjects with fasting glucose $>100 \mathrm{mg} / \mathrm{dl}$ before initiating treatment. A worse metabolic phenotype, lifestyle risk factors and family history of type 2 diabetes contributed to the risk.

\section{CONFLICT OF INTEREST}

The authors declare that they have no conflict of interest.

\section{REFERENCES}

1. WHO Statistical Information System (WHOSIS). World Health Organization. http://who.int/whosis/en/ Accessed 20 September 2015.

2. Cholesterol Treatment Trialists' (CTT) Collaborators, Kearney PM, Blackwell L, Collins R, et al, 2008 Efficacy of cholesterol-lowering therapy in 18,686 people with diabetes in 14 randomised trials of statins: a metaanalysis. Lancet 371: 117-125.

3. Cholesterol Treatment Trialists' (CTT) Collaboration, Baigent C, Blackwell L, Emberson J, et al, 2010 Efficacy and safety of more intensive lowering of LDL cholesterol: a meta-analysis of data from 170,000 participants in 26 randomised trials. Lancet 376: 1670-1681.

4. Sattar N, Preiss D, Murray HM, et al, 2010 Statins and risk of incident diabetes: a collaborative meta-analysis of randomised statin trials. Lancet 375: 735-742.

5. Preiss D, Seshasai SR, Welsh P, et al, 2011 Risk of incident diabetes with intensive-dose compared with moderate-dose statin therapy: a meta-analysis. JAMA 305: 2556-64.

6. Ridker PM, Pradhan A, MacFadyen JG, Libby P, Glynn
RJ, 2012 Cardiovascular benefits and diabetes risks of statin therapy in primary prevention: an analysis from the JUPITER trial. Lancet 380: 565-571.

7. Waters DD, Ho JE, Boekholdt SM, et al, 2013 Cardiovascular event reduction versus new-onset diabetes during atorvastatin therapy: effect of baseline risk factors for diabetes. J Am Coll Cardiol 61: 148-152.

8. Carter AA, Gomes T, Camacho X, Juurlink DN, Shah BR, Mamdani MM, 2013 Risk of incident diabetes among patients treated with statins: population based study. BMJ 346: f2610.

9. Emerging Risk Factors Collaboration, Sarwar N, Gao P, Seshasai SR, et al, 2010 Diabetes mellitus, fasting blood glucose concentration, and risk of vascular disease: a collaborative meta-analysis of 102 prospective studies. Lancet 375: 2215-2222.

10. US Food and Drug Administration. FDA drug safety communication: important safety label changes to cholesterol lowering statin drugs. http://www.fda. gov/Drugs/DrugSafety/ucm293101.html. Accessed 14 May 2016.

11. Waters DD, Guyton JR, Herrington DM, et al, 2004 Treating to New Targets (TNT) Study: does lowering low-density lipoprotein cholesterol levels below currently recommended guidelines yield incremental clinical benefit? Am J Cardiol 93: 154-158.

12. La Rosa JC, Grundy SM, Waters DD, et al, 2005 Intensive lipid lowering with atorvastatin in patients with stable coronary disease. N Engl J Med 352: 1425-1435.

13. Pedersen TR, Faergeman O, Kastelein JJ, et al, 2005 High-dose atorvastatin vs usual-dose simvastatin for secondary prevention after myocardial infarction: the IDEAL study: a randomized controlled trial. JAMA 294: 2437-2445.

14. Waters DD, Ho JE, De Micco DA, et al, 2011 Predictors of new-onset diabetes in patients treated with atorvastatin: results from 3 large randomized clinical trials. J Am Coll Cardiol 57: 1535-1545.

15. STROBE Statement. https://strobe-statement.org/index. php?id=available-checklists. Accessed 14 May 2016

16. American Diabetes Association 2015 Classification and diagnosis of diabetes. Diabetes Care 38 Suppl: S8-S16.

17. Harding AH, Wareham NJ, Bingham SA, et al 2008 Plasma vitamin $\mathrm{C}$ level, fruit and vegetable consumption, and the risk of new-onset type 2 diabetes mellitus: the European prospective investigation of cancer-Norfolk prospective study. Arch Intern Med 168: 1493-1499.

18. Cederberg H, Stančáková A, Yaluri N, Modi S, Kuusisto J, Laakso M, 2015 Increased risk of diabetes with statin treatment is associated with impaired insulin sensitivity and insulin secretion: a 6 year follow-up study of the METSIM cohort. Diabetologia 58: 1109-1117.

19. Mizuno K, Tajima N, Ohashi Y, Nakamura H, 2013 Is the risk of new-onset diabetes by statins associated with diet adherence? Int J Cardiol 166: 277.

20. Kohli P, Waters DD, Nemr R, et al, 2015 Risk of new- 
onset diabetes and cardiovascular risk reduction from high-dose statin therapy in pre-diabetics and non-prediabetics: an analysis from TNT and IDEAL. J Am Coll Cardiol 65: 402-404.

21. Alberti KG, Eckel RH, Grundy SM, et al, 2009 Harmonizing the metabolic syndrome: a joint interim statement of the International Diabetes Federation Task Force on Epidemiology and Prevention; National Heart, Lung, and Blood Institute; American Heart Association; World Heart Federation; International Atherosclerosis Society; and International Association for the Study of Obesity. Circulation 120: 1640-1645.

22. O'Neill S, O'Driscoll L, 2015 Metabolic syndrome: a closer look at the growing epidemic and its associated pathologies. Obes Rev16: 1-12.

23. Meigs JB, Cupples LA, Wilson PW, 2000 Parental transmission of type 2 diabetes: the Framingham Offspring Study. Diabetes 49: 2201-2207.

24. Valdez R, Yoon PW, Liu T, Khoury MJ, 2007 Family history and prevalence of diabetes in the U.S. population: the 6-year results from the National Health and Nutrition Examination Survey (1999-2004). Diabetes Care 30: 2517-2522.

25. Nakanishi N, Suzuki K, Tatara K, 2003 Alcohol consumption and risk for development of impaired fasting glucose or type 2 diabetes in middle-aged Japanese men. Diabetes Care 26: 48-54.

26. Knott C, Bell S, Britton A, 2015 Alcohol Consumption and the Risk of Type 2 Diabetes: A Systematic Review and Dose-Response Meta-analysis of More Than 1.9 Million Individuals From 38 Observational Studies. Diabetes Care 38: 1804-1812.

27. Mita T, Watada H, Nakayama S, et al, 2007 Preferable effect of pravastatin compared to atorvastatin on beta cell function in Japanese early-state type 2 diabetes with hypercholesterolemia. Endocr J 54: 441-447.

28. Ray K, 2013 Statin diabetogenicity: guidance for clinicians. Cardiovasc Diabetol 12 Suppl 1: S3.

29. Vallejo-Vaz AJ, Kondapally Seshasai SR, Kurogi K, et al, 2015 Effect of pitavastatin on glucose, HbA1c and incident diabetes: A meta-analysis of randomized controlled clinical trials in individuals without diabetes. Atherosclerosis 241: 409-418.

30. Yu Q, Chen Y, Xu CB, 2017 Statins and New-Onset Diabetes Mellitus: LDL Receptor May Provide a Key Link. Front Pharmacol 8: 372.

31. Fuentes F, Alcala-Diaz JF, Watts GF, et al, 2015 Statins do not increase the risk of developing type 2 diabetes in familial hypercholesterolemia: The SAFEHEART study. Int J Cardiol 201: 79-84. 